See Article page 68.

\section{Commentary: One is as good as three}

\author{
Constantine L. Athanasuleas, MD, FACC
}

Pulmonary artery endocarditis is rare, and prosthetic pulmonary valve endocarditis is rarer still. It presents a surgical challenge. In this issue of the Journal, Garcia-Rinaldi and colleagues ${ }^{1}$ applied an innovative method to replace a pulmonary bioprosthesis infected with methicillin-resistant Staphylococcus aureus. Because a cryopreserved aortic or pulmonic homograft was not available, they used a modified cadaveric cryopreserved pulmonary artery homograft that contained one cusp, created by excising a segment of the homograft containing the arterial wall and a cusp. Normally, the authors use this in venous reconstruction of the lower extremities. This monocusp pulmonary artery patch was used to replace the infected pulmonary bioprosthesis. The patient recovered uneventfully and at 2-year followup showed a fully competent valve.

The authors appropriately chose replacement rather than simple excision of the infected prosthesis with subsequent repeat valve replacement because of the adverse effects of right ventricular volume overload in the absence of the pulmonic valve.

The monocusp pulmonary valve has been applied in congenital heart surgery for years, using a variety of materials including autologous pericardium, bovine pericardium, aortic or pulmonary homografts, and prosthetic materials. $^{2-6}$ Pulmonary homograft monocusp reconstruction of the outflow tract in infants age $<1$ year with tetralogy of Fallot showed $85 \%$ freedom from replacement at 10 years. ${ }^{7}$ Conduits of all types are known to calcify and fail, especially in younger patients, and

\footnotetext{
From the Division of Cardiothoracic Surgery, Department of Surgery, University of Alabama at Birmingham, Birmingham, Ala.

Disclosures: The author reported no conflicts of interest.

The Journal policy requires editors and reviewers to disclose conflicts of interest and to decline handling or reviewing manuscripts for which they may have a conflict of interest. The editors and reviewers of this article have no conflicts of interest.

Received for publication Jan 21, 2021; revisions received Jan 21, 2021; accepted for publication Jan 25, 2021; available ahead of print Jan 30, 2021.

Address for reprints: Constantine L. Athanasuleas, MD, FACC, 1720 Second Ave S, THT 720, Birmingham, AL 35294-00065 (E-mail: cathanasuleas@uab.edu). JTCVS Techniques 2021;6:71-2

2666-2507

Copyright (C) 2021 The Authors. Published by Elsevier Inc. on behalf of The American Association for Thoracic Surgery. This is an open access article under the CC BY-NCND license (http://creativecommons.org/licenses/by-nc-nd/4.0/).

https://doi.org/10.1016/j.xjtc.2021.01.036
}

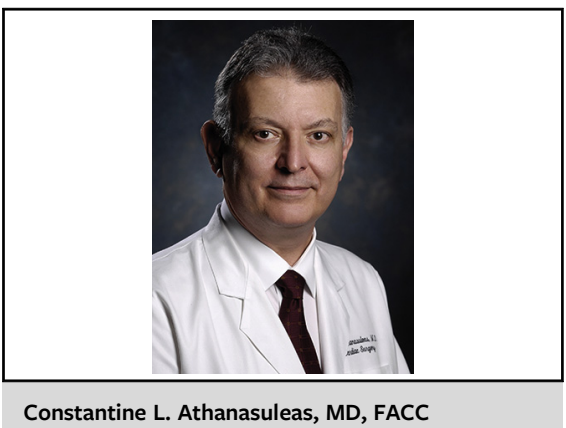

CENTRAL MESSAGE

Innovation is key to success in management of prosthetic pulmonary endocarditis using a cryopreserved pulmonary monocusp.

reoperations are not uncommon. Based on the current literature, it is impossible to extrapolate the fate of the monocusp patch in the 32-year-old patient described in this report.

The nonuse of any prosthetic material was crucial to the successful outcome. The described operation seems simple. Curiously, the monocusp seemed to adequately fill the pulmonary artery and maintain valve competence. In one study, the mean Doppler echocardiographic determination of pulmonary valve orifice area in normal adults was $3.01 \pm 0.36 \mathrm{~cm}^{2}\left(2.02 \pm 0.20 \mathrm{~cm}^{2} / \mathrm{m}^{2}\right)$ with a modest correlation with body surface area. ${ }^{8}$ No difference was observed between males and females. Normally, this area is covered by 3 pulmonic leaflets. The authors chose a monocusp patch that worked well and must have covered the area adequately, because there was no pulmonic insufficiency immediately postoperatively. Perhaps they could have assembled a patch with 2 leaflets if one had not sufficed. I suspect that intuition and good surgical judgment guided their choice.

Garcia-Rinaldi and colleagues are to be congratulated on a very innovative approach to a difficult problem.

\section{References}

1. García-Rinaldi R, Becerra-Román I, Rosario C, Olmeda S, Reyes-Torres P. Replacement of an endocarditic bioprosthetic pulmonary valve with a monocusp cryopreserved pulmonary artery patch. J Thorac Cardiovasc Surg Tech. 2021;6: 68-70.

2. Abdulali SA, Silverton NP, Yakirevich VS, Ionescu MI. Right ventricular outflow tract reconstruction with a bovine pericardial monocusp patch: long-term clinical and hemodynamic evaluation. J Thorac Cardiovasc Surg. 1985;89:764-71. 
3. Anagnostopoulos P, Azakie A, Natarajan S, Alphonso N, Brook MM, Karl TR. Pulmonary valve cusp augmentation with autologous pericardium may improve early outcome for tetralogy of Fallot. J Thorac Cardiovasc Surg. 2007;133:640-7.

4. Eguchi S, Irisawa T, Asano K-I. Use of valve-retaining homograft and heterograft patch for reconstruction of right ventricular outflow tract: clinical experience in tetralogy of Fallot. Ann Thorac Surg. 1972;14:615-25.

5. Gundry SR, Razzouk AJ, Boskind JF, Bansal R, Bailey LL. Fate of the pericardial monocusp pulmonary valve for right ventricular outflow tract reconstruction: early function, late failure without obstruction. J Thorac Cardiovasc Surg. 1994;107: 908-13.
6. Miyazaki T, Yamagishi M, Nakashima A, Fukae K, Nakano T, Yaku H, et al. Expanded polytetrafluoroethylene valved conduit and patch with bulging sinuses in right ventricular outflow tract reconstruction. J Thorac Cardiovasc Surg. 2007; 134:327-32.

7. Nath DS, Nussbaum DP, Yurko C, Ragab OM, Shin AJ, Kumar SR, et al. Pulmonary homograft monocusp reconstruction of the right ventricular outflow tract: outcomes to the intermediate term. Ann Thorac Surg. 2010;90:42-9.

8. Singh B, Mohan JC. Doppler echocardiographic determination of aortic and pulmonary valve orifice areas in normal adult subjects. Int J Cardiol. 1992;37: 73-8. 